\title{
Growth, Form and Quambalaria Shoot Blight Tolerance of Spotted Gum in North-eastern New South Wales, Australia
}

\author{
By I. G. Johnson ${ }^{\left.1,{ }^{*}\right)}$, A. J. CARNEGIE ${ }^{1)}$ and M. Henson ${ }^{2)}$
}

(Received $7^{\text {th }}$ August 2008)

\begin{abstract}
A young provenance/progeny trial of spotted gums, which are major hardwood plantation species in subtropical eastern Australia, was studied for growth, form, and damage from Quambalaria shoot blight. The trial contained a wide range of genotypes, mainly of Corymbia citriodora subsp. variegata, with between one and 21 families per provenance. Genetic parameters were calculated from 23 provenances with four or more families. Provenances superior for growth included four well-represented $C$. citriodora subsp. variegata provenances, all from south-east Queensland, which also had a high proportion of superior families. Overall, Queensland provenances had significantly higher mean diameter and height than those from New South Wales (NSW), although there were several superior NSW families. Provenances superior for growth also displayed good straightness and relatively fine branching. Relatively low Quambalaria shoot blight damage was recorded for four Queensland provenances and one coastal NSW provenance, which all had high proportions of families with low damage. Provenances that were putative intergrades between $C$. citriodora subsp. variegata and C. maculata tended to have high damage levels. However, some mediocre provenances contained superior families potentially useful for breeding. Regressions of Quambalaria damage index (QDI) on latitude, and mean height growth on QDI, were highly significant and moderately strong ( 0.51 and 0.58 , respectively), indicating increasing damage in more southern material, and a retarding effect (although not striking) of damage on growth. Individual heritability estimates were low (zero to 0.14) for growth and form, and moderate for QDI (0.31). The genetic correlations for QDI with growth traits were strong and negative $(-0.77$ and -0.88$)$, supporting a strategy of selecting vigorous trees for breeding programs from provenances and families superior for these traits.
\end{abstract}

Key words: Spotted gum, Corymbia, Quambalaria pitereka, Quambalaria shoot blight, growth, form, genetic relationships, provenance trial, family trial.

\section{Introduction}

The spotted gums are amongst the most important timber species in natural forests in sub-tropical Australia (LEE, 2007; BoLAND et al., 1984). In natural forests, spotted gums of all species grow to tall trees of

\footnotetext{
1) Forest Resources Research, NSW Department of Primary Industries, PO Box 100, Beecroft, NSW 2119, Australia.

$\left.{ }^{2}\right)$ Land Management and Forestry Services, Forests NSW, PO Box J19, Coffs Harbour, NSW 2450, Australia.

*) Corresponding author: I. G. Johnson. Tel. 610298720161 , Fax 6129871 6941. E-Mail: ianj@ئf.nsw.gov.au
}

up to $35-45 \mathrm{~m}$ in height and 1 to $1.3 \mathrm{~m}$ in diameter on favourable sites, and up to $20-30 \mathrm{~m}$ in height on poorer sites (BoLAND et al., 1984). They typically have a long, straight bole. The timber from natural stand trees machines and finishes well, and has a wide range of uses, from engineering applications, poles, handles, general framing and construction, to joinery, furniture, and turnery (Bootle, 1983). Before 1995 the spotted gums were classified in the genus Eucalyptus, under the Subgenus Corymbia (PRYOR and JoHnson, 1971). HILL and JOHNSON (1995) proposed placing them in a separate genus, Corymbia, Section Politaria, recognising the species C. citriodora, C. maculata, C. variegata, and C. henryi. MCDONALD and BEAN (2000) established C. citriodora subsp. variegata and C. citriodora subsp. citriodora as two chemotypes of $C$. citriodora. In this paper we use the genus Corymbia and the spotted gum species and subspecies identified by MCDONALD and BEAN (2000).

Due to the likelihood of future reductions in wood supply from natural stands, and the species' adaptability over a wide range of sites, spotted gums (particularly C. citriodora subsp. variegata) have become important solid wood plantation species in sub-tropical eastern Australia (Queensland and NSW) in the last 12 years (LEE, 2007). Over 104,000 ha of hardwood plantations are established in subtropical eastern Australia (GAVRAN and PARSONS, 2008). Approximately $21 \%$ of this is spotted gum (NichOLs et al., 2008).

A major disease of spotted gums is Quambalaria shoot blight, caused by Quambalaria pitereka (= Ramularia pitereka). This disease became endemic in spotted gum plantations in north-eastern NSW and south-east Queensland within three years of large-scale planting (SElF et al., 2002; CARNEGIE, 2007b). The pathogen infects immature leaves and growing shoots, causing them to distort and die (WALKER and BERTUS, 1971; PEGG et al., 2008). Repeated infection results in proliferation of leaders, causing significant reductions in height growth and stem malformations (SIMPSON et al., 1997; Simpson, 2000; CARNEGIE, 2007a, b; PEGG et al., 2008).

Quambalaria shoot blight is common along the eastern coast of Australia, associated with severe damage to seedlings and young regeneration in native forests, and has been known from nurseries in NSW since the mid 1950s (WALKer and Bertus, 1971; Bertus and WALKer, 1974; OLD, 1990). The disease is also common in young spotted gum regeneration in native stands adjacent to commercial plantations, and these natural trees provide a source of inoculum for many plantations (PEGG et al., 2009). STONE et al. (1998) predicted that specific management of the disease would be needed if Corymbia 
species were to be planted on a commercial scale in northern NSW, and CARNEGIE (2007b) recently outlined a range of management options, including tree improvement. SELF et al. (2002) considered Quambalaria shoot blight to be one of the most significant health problems facing hardwood forestry in eastern Australia. As a consequence, the planting of spotted gums was temporarily stopped in Queensland (SELF et al., 2002; DICKINSON et al., 2004) and dramatically reduced in NSW for several years (CARNEGIE, 2007b). The disease is still considered the most significant hindrance to profitable spotted gum plantations in subtropical and tropical Australia (CARNEGIE, 2007b; PEGG et al., 2008, 2009).

Variation in susceptibility of spotted gum genotypes to Quambalaria shoot blight was observed, at the provenance level, within a year or two of planting in young trials in NSW and Queensland. In a "crop loss" study on three sites in north-east NSW, considering fungal foliar damage scores summed over all treatments, C. citriodora subsp. variegata from Warwick, Queensland (an inland provenance) was two to four times more damaged than $C$. maculata from the NSW south coast (SIMPSON et al., 1997). In south-east Queensland trials, C. citriodora subsp. variegata provenances from higher rainfall coastal areas showed superior tolerance to those from areas with lower rainfall (NIKLES et al., 2000). Wide variation in susceptibility was also observed early in Forests NSW commercial spotted gum plantations planted with single provenance seedlots (CARNEGIE and CANT, Forests NSW, 1997, unpublished data), and this variation was suspected to occur at the family level.

SELF et al. (2002) found Richmond Range (NSW) C. citriodora subsp. variegata to be the least infected of eight spotted gum provenances in a small inoculated trial in south-east Queensland. Woondum provenance (south-east Queensland) was moderately susceptible, and the most severely infected provenance was from Presho, western Queensland. SELF et al. (2002) noted that significant variation in Quambalaria shoot blight tolerance existed within provenances. In a majority of taxon x site trials in Queensland, containing a limited number of spotted gum northern species provenances per site, Woondum (south-east Queensland) C. citriodora subsp. variegata material was significantly less damaged by Quambalaria shoot blight than the other provenances (DICKINSON et al., 2004). It also had the best height growth on nine sites. Eight $C$. henryi provenances displayed relatively poor Quambalaria shoot blight tolerance in these trials.

Prior to commencing this study there was a paucity of published data on genetic variability and genetic parameters for spotted gums, notably $C$. citriodora subsp. variegata. In 1999, a large provenance-family trial of spotted gum (predominantly C. citriodora subsp. variegata) was established, as part of a breeding population, on a site in north-east NSW typical of much of the land planted to spotted gums in that area. Objectives of this trial were to study growth, form, and Quambalaria shoot blight tolerance at various genetic levels - provenance, family, and individual - and identify superior genotypes for commercial deployment.

\section{Methods}

\section{Seedlots in trial}

The progeny trial contained open-pollinated seedlots collected from 194 individual mature spotted gum trees in natural forest in NSW (113 trees) and south-east Queensland (81 trees). The parent trees occurred mainly in "core areas" of $C$. citriodora subsp. variegata between latitudes $26^{\circ} \mathrm{S}$ and $30^{\circ} \mathrm{S}$ (MCDONALD and BEAN, 2000), in NSW sub-coastal ranges and south-east Queensland. Some individual tree collections in the Kempsey area (about $31^{\circ} \mathrm{S}$ ) may have been from C. maculata or intergrades of this species with $C$. citriodora subsp. variegata (based on taxonomy of HiLl and JoHnson, 1995). The seedlots overall represented 24 provenances in NSW and 7 provenances in Queensland, as defined by the state forests where collections were carried out (Table 1). Two NSW commercial bulk control C. citriodora subsp. variegata seedlots, from South Toonumbar State Forest $\left(28^{\circ} 30^{\prime} \mathrm{S}\right)$ and Bagawa State Forest $\left(30^{\circ} 08^{\prime} \mathrm{S}\right)$, were also planted in the trial.

\section{Trial design and establishment}

The trial consisted of 5 replicates of 5 -tree line plots of each seedlot, planted in a resolvable 14 row x 14 column design with an espacement of $4.0 \times 2.5 \mathrm{~m}$. The design was generated using Alpha+ software (WILLIAMs and MATHESON, 1994). The trial was located at $28^{\circ} 52^{\prime} \mathrm{S}$ latitude and $152^{\circ} 38^{\prime} \mathrm{E}$ longitude, on a purchased grazing property about $13 \mathrm{~km}$ south-south-east of Bonalbo in north-eastern NSW. It was on the gentle to moderately sloping mid-lower east-facing slopes of a broad ridge at altitude 170-190 m ASL. Mean annual rainfall (MAR) for Bonalbo (Commonwealth Bureau of Meteorology data for 58 years ex Bonalbo Post Office) is about $1029 \mathrm{~mm}$. The existing vegetation was predominantly partially-improved pasture. Soils on the trial site were of fairly low fertility, predominantly Yellow Podzolics on sandstone parent material, with a shallow $(15 \mathrm{~cm})$ darkcoloured clay loam A1 horizon, over a yellowish-brown medium clay B2 horizon, with grey-brown mottles.

Severe frosts affected the trial in early June 2000, damaging many trees, mainly in the lower altitude replicates. Most or all of the foliage was scorched on the smaller trees $(<2 \mathrm{~m}$ tall), but the crowns of most trees had largely recovered by autumn 2001, when the 25-month Quambalaria shoot blight assessment (below) was carried out. It is likely that the growth rate and form of severely affected trees were retarded and damaged for a period by the frosting.

\section{Assessments}

A heavy infestation of Quambalaria shoot blight occurred in late summer-autumn 2001, following a very wet 5-month period. Disease was assessed in the first three replicates of the family trial in April 2001, at age 25 months from planting. Generally, the first three trees in each 5-tree plot were assessed, avoiding obvious runts and trees whose crowns had been killed and were reshooting from lignotubers at the base after severe frost damage. In such cases, different trees in the plot were assessed to make up the three trees. 
Each tree was scored for incidence and severity of Quambalaria shoot blight: incidence is the percentage of the immature crown (leaves and shoots) carrying any $Q$. pitereka infection, either as white fungal pustules or crinkled (or dead) shoots and leaves, while severity is the percentage of the area of the infected shoots/leaves that is damaged, scored in classes of 1 to 8 depending on the percentage of leaf area affected:

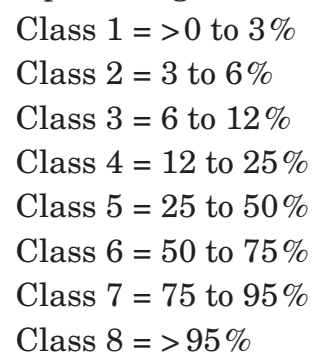

Only the immature parts of trees (leaves and shoots) were assessed since the pathogen infects this part of the plant (WALKer and BerTus, 1971). As such, the whole crown was not assessed (i.e. not the mature leaves, branches or stem). For each tree with infection, a Quambalaria Damage Index (QDI), expressed as a percentage, was calculated as follows:

$\mathrm{QDI}=($ Incidence $*$ Median value of Severity Class $) / 100$

This was considered to express the true extent of $Q$. pitereka damage to the immature crown of the tree, and to provide a better means of comparisons among seedlots. This index is similar to, and a precursor of, the Crown Damage Index (CDI) described by STONE et al. (2003); however, the CDI assesses the whole crown for pest and disease damage, including mature and immature foliage.

Diameter at breast height (DBHOB, $1.3 \mathrm{~m}$ above ground) and total height (HT) were assessed at age 41 months from planting, on trees assessed for Quambalaria shoot blight. On trees forking below $1.3 \mathrm{~m}$ height, the largest diameter stem was measured. Two major form traits were also scored on these trees, both on a scale of 1 to 6 , with score 6 assigned to the best trees and score 1 to the poorest trees in the trial, as follows:

Stem straightness (STR), a subjective score, with essentially straight trees scoring 6 and very crooked trees scoring 1, based on methods developed by ELDRIDGE (1973). Trees of intermediate straightness were given scores of 2 to 5 , with standards for each score determined by "cruising" the trial before assessment.

Branch thickness (BRT), with score 6 applied to trees with predominantly very fine branches and score 1 to trees with multiple thick branches. This was a more objective scoring system, with defined standards for each score.

Additionally, the number of occurrences of forking in the main stem and number of ramicorn branches were counted for each tree (ramicorn: defined as a very steepangled branch, previously forming a competing leader, but now bypassed by the dominant leader).

During this assessment, trees considered to be $C$. henryi (based on juvenile leaf size) were noted in multiple plots of each of 10 families, from Ewingar, Mt Belmore,
Mt Pikapene, Sugarloaf (NSW), and Lockyer (Queensland) provenances. These locations were adjacent to the mainly lowland range of $C$. henryi which extends from near Grafton (NSW) into the south-east corner of Queensland (HiLL and JoHnson, 1995). Data from these families were used to give a general indication of the performance of $C$. henryi compared with that of $C$. citriodora subsp. variegata.

\section{Analyses}

Analyses of variance: No estimates of tree volume using $\mathrm{DBHOB}$ and HT data were attempted, due to the small size of many of the trees, as such estimates would have been practically meaningless in many cases. Normality of individual tree data for all families for each of the traits DBHOB, HT, STR, BRT, and QDI was checked using the SAS Univariate Procedure (SAS InstituTe, 1990). Residuals for DBHOB, HT and STR (generated from an initial analysis of variance including replicate, seedlots, rows, columns, and the family x replicate interaction) were essentially normally distributed, based on measures of skewness and kurtosis and normal probability plots. Residuals for QDI were not normally distributed, and data for this trait were transformed for analysis using arcsin square root transformation, which improved normality. Transformations did not improve the normality of BRT data, and the raw data were analysed. Homoscedasticity for all traits was indicated by approximately random distributions of plotted residuals against predicted values about zero (SAS Plot Procedure). No biologically anomalous outliers were indicated from these plots.

The individual tree data set including all spotted gum families (but excluding controls) was analysed using the SAS Mixed analysis of variance procedure (SAS InSTITUTE, 1996), to determine the significance of differences among provenances and families within provenances for each trait, and estimate least squares means for provenances. The following family model was used:

$$
\begin{aligned}
\mathrm{y}_{\mathrm{ijklm}}= & \mu+\mathrm{B}_{\mathrm{i}}+\mathrm{P}_{\mathrm{j}}+\mathrm{F}_{\mathrm{k}}\left(\mathrm{P}_{\mathrm{j}}\right)+\mathrm{R}_{\mathrm{l}}\left(\mathrm{B}_{\mathrm{i}}\right) \\
& +\mathrm{C}_{\mathrm{m}}\left(\mathrm{B}_{\mathrm{i}}\right)+\mathrm{B}_{\mathrm{i}} \mathrm{F}_{\mathrm{k}}\left(\mathrm{P}_{\mathrm{j}}\right)+\mathrm{e}_{\mathrm{ijklm}}
\end{aligned}
$$

where $\mu$ is the overall mean; $B_{i}$ is the random effect of the $i^{\text {th }}$ replicate; $P_{j}$ is fixed effect of the $j^{\text {th }}$ provenance; $\mathrm{F}_{\mathrm{k}}\left(\mathrm{P}_{\mathrm{j}}\right)$ is the random effect of the $\mathrm{k}^{\text {th }}$ family nested in the $j^{\text {th }}$ provenance; $R_{l}\left(B_{i}\right)$ is the random effect of the $l^{\text {th }}$ row in the $i^{\text {th }}$ replicate; $\mathrm{C}_{\mathrm{m}}\left(\mathrm{B}_{\mathrm{i}}\right)$ is the random effect of the $\mathrm{m}^{\text {th }}$ column in the $i^{\text {th }}$ replicate; $\mathrm{B}_{\mathrm{i}} \mathrm{F}_{\mathrm{k}}\left(\mathrm{P}_{\mathrm{j}}\right)$ is the random interaction between the $i^{\text {th }}$ replicate and the $\mathrm{k}^{\text {th }}$ family in the $\mathrm{j}^{\text {th }}$ provenance (or plot); $\mathrm{e}^{\mathrm{ijklm}}$ is the random error of the ijklm ${ }^{\text {th }}$ tree.

Analyses of pre-planned contrasts between sets of provenances were carried out using model 1 above.

Least squares means for all individual seedlots (including the controls) were estimated using the following model:

$$
\mathrm{y}_{\mathrm{iklm}}=\mu+\mathrm{F}_{\mathrm{k}}+\mathrm{B}_{\mathrm{i}}+\mathrm{R}_{\mathrm{l}}\left(\mathrm{B}_{\mathrm{i}}\right)+\mathrm{C}_{\mathrm{l}}\left(\mathrm{B}_{\mathrm{i}}\right)+\mathrm{B}_{\mathrm{i}} \mathrm{F}_{\mathrm{k}}+\mathrm{e}_{\mathrm{iklm}}
$$

where $\mu$ is the overall mean; $F_{k}$ is the fixed effect of the $\mathrm{k}^{\text {th }}$ seedlot; $\mathrm{B}_{\mathrm{i}}$ is the random effect of the $\mathrm{i}^{\text {th }}$ replicate; $R_{l}\left(B_{i}\right)$ is the random effect of the $1^{\text {th }}$ row in the $i^{\text {th }}$ repli- 
cate; $\mathrm{C}_{1}\left(\mathrm{~B}_{\mathrm{i}}\right)$ is the random effect of the $\mathrm{l}^{\text {th }}$ column in the $\mathrm{i}^{\text {th }}$ replicate; $\mathrm{B}_{\mathrm{i}} \mathrm{F}_{\mathrm{k}}$ is the random interaction between the $\mathrm{i}^{\text {th }}$ replicate and the $\mathrm{k}^{\text {th }}$ family (or plot); $\mathrm{e}_{\mathrm{iklm}}$ is the random error of the iklm ${ }^{\text {th }}$ tree.

Genetic parameters: Only families in better represented provenances (4 or more families per provenance) were used to estimate genetic parameters; control seedlots were also excluded, giving 178 families in 23 provenances. Variance components for heritability estimation were generated for each trait, using model [1] above. Individual heritability and heritability of family means, on a family-within-provenance basis, were estimated separately for traits.

$$
\mathrm{h}^{2}{ }_{\mathrm{i}}=2.5^{*} \sigma_{\mathrm{f}}^{2} /\left(\sigma_{\mathrm{f}}^{2}+\sigma_{\mathrm{p}}^{2}+\sigma_{\mathrm{e}}^{2}\right)
$$

Heritability of family means was estimated as:

$$
\mathrm{h}_{\mathrm{f}}^{2}=\sigma_{\mathrm{f}}^{2} /\left(\sigma_{\mathrm{f}}^{2}+\left[\sigma_{\mathrm{p}}^{2} / \mathrm{r}\right]+\left[\sigma_{\mathrm{e}}^{2} / \mathrm{rn}\right]\right)
$$

where $\sigma_{\mathrm{f}}^{2}$ is the family within provenance variance, $\sigma^{2}{ }_{\mathrm{p}}$ is the plot (or family $x$ replicate) component, $\sigma_{e}^{2}$ is the residual variance, $r$ is number of replicates, and $n$ is mean number of trees per plot.

The coefficient of relationship used in computation of the individual tree heritability values was assumed to be 0.4 , rather than the value of 0.25 used for half-sib families. This was because open-pollinated families from natural eucalypt stands generally carry a degree of inbreeding resulting from selfing and neighbourhood inbreeding (ELDRIDGE et al., 1994; WILLIAMs and MATHESON, 1994).

Additive genetic correlations $\left(\mathrm{r}_{\mathrm{A}}\right)$ between growth traits and transformed QDI were estimated for 178 families in the well-represented provenances, as were used for heritability estimation. These correlations were estimated using ASREML (GILMOUR et al., 2002), where variance components were estimated from an individual tree model with similar random and fixed terms as in Equation 1, with the exception that a Tree term $\left(\mathrm{T}_{\mathrm{k}}\right)$ linked to a pedigree was used instead of the family term $\mathrm{F}_{\mathrm{k}}$ in Equation 1, and eijklm represents residual error. The additive genetic correlations for paired traits were estimated from Equation [5].

$$
\mathrm{r}_{\mathrm{axy}}=\sigma_{\mathrm{axy}}^{2} /\left(\sqrt{ }\left(\sigma_{\mathrm{ax}}^{2} * \sigma_{\mathrm{ay}}^{2}\right)\right)
$$

Where $r_{a x y}$ is the genetic correlation between traits $\mathrm{x}$ and $y ; \sigma^{2}{ }_{a x y}$ is the additive covariance of traits $\mathrm{x}$ and $\mathrm{y}$; $\sigma^{2}{ }_{a x}$ and $\sigma^{2}{ }_{a y}$ are additive variance components for traits $\mathrm{x}$ and $\mathrm{y}$. Phenotypic correlations among all growth and form traits were estimated for the same families using the SAS CORR Procedure (SAS INSTITUTE, 1990).

Relationships between Quambalaria shoot blight, growth and provenance origins: Coefficients of determination $R^{2}$ for Type II linear regression between the least-squares means for three growth traits and QDI were calculated using PAST software (HAMMER et al., 2001), for all the spotted gum families (194 families), and for the 23 better represented provenances (see above), in replicates 1 to 3 . $\mathrm{R}^{2}$ for regressions of QDI on provenance latitude and altitude were calculated using the SAS REG Procedure (SAS Institute, 1990). Mean annual rainfall and summer rainfall (October-March) for each provenance were estimated using ANUCLIM V.
5.1 (Houlder et al., 2001). Regression of mean QDI for provenances on mean annual and summer rainfall of provenance origins was also calculated.

\section{Results}

\section{Overall growth, form and disease damage}

Mean tree DBHOB and height were $3.8 \mathrm{~cm}(0.04 \mathrm{SE})$ and $4.3 \mathrm{~m}( \pm 0.03 \mathrm{SE})$ respectively (Table 1$)$. Mean QDI was $40.4 \%( \pm 1.05 \mathrm{SE})$, with a wide range of individual tree values from $0.0 \%$ to $97.5 \%$. Wide variation in QDI also occurred within many families and between families in some provenances. Twenty-seven percent (27\%) of assessed trees had between 1 and 4 forks, although the mean number of forks was low, at 0.3. Ramicorn branches were more numerous: $46 \%$ of trees were affected, with between 1 and 3 ramicorns, and an average of 0.64 per tree (Table 1).

\section{Provenance and family performance}

There were highly significant differences among provenance means $(P<0.005)$ for all growth and form traits and Quambalaria shoot blight in the 3-replicate spotted gum family data set (194 families). These results were closely paralleled for the smaller 178-family data set, containing only better represented provenances (data not presented). Differences between families-within-provenances were also significant $(P<0.05)$ for DBHOB, height, and for transformed QDI, but not for STR or BRT $(P<0.39$ and 0.25 , respectively) (Table 2 ). Provenance least squares means for growth, form, numbers of forks and ramicorns, and QDI are shown in Table 1.

Growth traits: Differences in mean diameter (DBHOB) and height between provenances were generally not marked, and there were few notably superior or poor provenances. Seven provenances performed well for both DBHOB and height, including Brooyar, Wolvi, Wondai, and Woondum (Queensland) and Sugarloaf, Mt Pikapene and Ewingar (NSW), with mean values well above the trial averages (Table 1). The well-known Woondum provenance was not superior in diameter to the other six Queensland provenances as a group (SAS MIXED Contrasts $P=0.70$ ), but was superior to all other (30) provenances combined. Additionally, Home and Ingalba ranked well for height particularly (means over $4.6 \mathrm{~m}$ ), and Home had four families with mean height $>5.0 \mathrm{~m}$.

The superior NSW provenances for both traits included only six families, of which five were putative $C$. henryi, with mean DBHOB of $4.34 \mathrm{~cm}$ and mean height of $4.69 \mathrm{~m}$. The four superior Queensland provenances (all of C. citriodora subsp. variegata) contained among them 21 families (out of 49 families) with clearly superior mean DBH (over $4.3 \mathrm{~cm}$ ) and 21 families with superior mean height (over $4.8 \mathrm{~m}$ ), often the same families. (Family means not presented in this paper.) The topranking family for both $\mathrm{DBHOB}$ and height was from Home provenance (means $5.82 \mathrm{~cm}$ and $6.21 \mathrm{~m}$ ). Other outstanding families combining means over 5.0 for both traits were rare (four families), occurring in Brooyar, Ewingar, Richmond Range, and Woondum provenances. 
Table 1. - Origin data, and mean values for growth and form traits (at 41 months) and Quambalaria shoot blight damage (QDI, at 25 months) of spotted gum provenances (in alphabetical order).

\begin{tabular}{|c|c|c|c|c|c|c|c|c|c|c|c|c|}
\hline PROVENANCE & $\begin{array}{c}\text { Latitude } \\
\text { (Deg Min) }\end{array}$ & $\begin{array}{l}\text { Longitude } \\
\text { (Deg Min) }\end{array}$ & $\begin{array}{c}\text { Mean } \\
\text { Alt } \\
\text { (m) }\end{array}$ & $\begin{array}{l}\text { MAR } \\
(\mathrm{mm})\end{array}$ & $\begin{array}{c}\text { No. of } \\
\text { families }\end{array}$ & $\begin{array}{c}\text { DBHOB } \\
(\mathrm{cm})\end{array}$ & $\begin{array}{l}\text { Tot } \\
\text { HT } \\
(\mathrm{m}) \\
\end{array}$ & $\begin{array}{c}\text { STR } \\
\text { (point) }\end{array}$ & $\begin{array}{c}\text { BRT } \\
\text { (point) }\end{array}$ & $\begin{array}{c}\text { No. of } \\
\text { FORKS }\end{array}$ & $\begin{array}{c}\text { No. of } \\
\text { RAMICS }\end{array}$ & $\begin{array}{l}\text { QDI }^{3} \\
(\%)\end{array}$ \\
\hline Bagawa SF, NSW & 3010 & 15257 & 343 & 1563 & 5 & 3.13 & 3.80 & 2.85 & 3.70 & 0.44 & 1.07 & 69.24 \\
\hline Boonanghi SF, NSW ${ }^{1}$ & 3103 & 15231 & 443 & 1551 & 6 & 3.69 & 3.92 & 2.96 & 4.08 & 0.76 & 0.98 & 67.26 \\
\hline Boundary Creek SF, NSW & 2957 & 15234 & 481 & 1197 & 10 & 3.95 & 4.15 & 3.15 & 3.98 & 0.35 & 0.81 & 50.79 \\
\hline Brooyar, Queensland (SF 82) & 2610 & 15230 & 90 & 1143 & 7 & 4.32 & 5.02 & 3.53 & 4.92 & 0.19 & 0.19 & 17.81 \\
\hline Chaelundi SF, NSW & 2956 & 15223 & 680 & 1069 & 3 & 3.80 & 4.30 & 3.55 & 4.40 & 0.16 & 0.72 & 32.70 \\
\hline Dalmorton SF, NSW & 2949 & 15224 & 648 & 1104 & 6 & 3.68 & 4.13 & 3.35 & 4.35 & 0.40 & 0.64 & 60.25 \\
\hline Esk, Queensland (SF 531) & 2718 & 15220 & 300 & 850 & 9 & 3.21 & 4.15 & 2.98 & 4.99 & 0.27 & 0.52 & 50.07 \\
\hline Ewingar SF, NSW ${ }^{2}$ & 2903 & 15228 & 483 & 1187 & 3 & 4.08 & 4.59 & 2.95 & 4.20 & 0.26 & 0.67 & 40.96 \\
\hline Gilgurry SF, NSW & 2850 & 15216 & 670 & 1148 & 2 & 3.63 & 3.89 & 3.08 & 3.67 & 0.24 & 1.29 & 78.63 \\
\hline Girard SF, NSW & 2853 & 15218 & 675 & 1270 & 2 & 3.16 & 3.96 & 3.13 & 4.24 & 0.29 & 0.71 & 31.10 \\
\hline Grange SF, NSW & 2928 & 15235 & 528 & 1294 & 6 & 3.05 & 3.60 & 2.81 & 3.87 & 0.34 & 1.21 & 54.30 \\
\hline Home LA, Toolara SF, Queensland & 2605 & 15243 & 137 & 1143 & 13 & 3.96 & 4.64 & 3.82 & 4.73 & 0.22 & 0.34 & 2.04 \\
\hline Ingalba SF, NSW ${ }^{1}$ & 3051 & 15245 & 166 & 1388 & 4 & 3.99 & 4.68 & 3.24 & 4.29 & 0.32 & 0.41 & 45.21 \\
\hline Kangaroo River SF, NSW & 3005 & 15252 & 399 & 1452 & 8 & 3.79 & 4.14 & 3.11 & 3.96 & 0.36 & 1.02 & 41.95 \\
\hline Lockyer, Queensland (SF 616) ${ }^{2}$ & 2728 & 15217 & 150 & 850 & 10 & 3.84 & 4.42 & 3.23 & 4.34 & 0.21 & 0.43 & 37.24 \\
\hline Lower Bucca SF, NSW & 3010 & 15304 & 200 & 1582 & 4 & 3.85 & 4.29 & 3.38 & 4.47 & 0.33 & 0.64 & 27.70 \\
\hline Mt Pikapene SF, NSW ${ }^{2}$ & 2903 & 15240 & 235 & 1157 & 1 & 4.33 & 4.63 & 3.11 & 4.02 & 0.22 & 0.33 & 30.10 \\
\hline Newry SF, NSW & 3032 & 15254 & 140 & 1716 & 1 & 2.31 & 3.34 & 2.54 & 3.93 & 0.57 & 0.43 & 0.00 \\
\hline Ramornie SF, NSW & 2943 & 15236 & 425 & 1222 & 6 & 3.73 & 4.23 & 3.21 & 4.06 & 0.42 & 0.72 & 38.02 \\
\hline Richmond Ra SF, NSW & 2840 & 15242 & 405 & 1233 & 13 & 3.44 & 3.99 & 3.23 & 3.98 & 0.34 & 0.77 & 46.22 \\
\hline Sheas Nob SF, NSW & 3003 & 15237 & 653 & 1315 & 4 & 3.98 & 4.47 & 3.32 & 4.31 & 0.18 & 0.77 & 32.02 \\
\hline Sugarloaf SF, NSW ${ }^{2}$ & 2856 & 15237 & 215 & 1083 & 2 & 4.56 & 4.85 & 3.70 & 4.66 & 0.28 & 0.44 & 40.60 \\
\hline Tamban SF, NSW ${ }^{1}$ & 3056 & 15248 & 113 & 1323 & 4 & 3.39 & 3.76 & 2.61 & 4.07 & 0.34 & 1.22 & 68.14 \\
\hline Washpool SF, NSW & 2917 & 15227 & 428 & 1147 & 5 & 2.92 & 3.44 & 3.25 & 4.24 & 0.30 & 0.61 & 56.84 \\
\hline Wedding Bells SF, NSW & 3004 & 15310 & 82 & 1528 & 6 & 3.73 & 4.27 & 3.56 & 4.19 & 0.29 & 0.59 & 12.50 \\
\hline Wolvi LA, Toolara SF, Queensland & 2607 & 15247 & 120 & 1148 & 13 & 4.13 & 4.64 & 3.71 & 4.50 & 0.24 & 0.41 & 6.04 \\
\hline Wondai, Queensland (SF 12) & 2622 & 15149 & 350 & 800 & 8 & 4.20 & 4.84 & 3.64 & 4.73 & 0.14 & 0.42 & 28.55 \\
\hline Woondum, Queensland (SF 393) & 2615 & 15249 & 400 & 1600 & 21 & 4.01 & 4.49 & 3.70 & 4.52 & 0.22 & 0.40 & 5.72 \\
\hline Yessabah SF, NSW ${ }^{1}$ & 3108 & 15237 & 232 & 1418 & 6 & 3.36 & 3.87 & 2.83 & 3.89 & 0.41 & 1.00 & 73.54 \\
\hline Routine Bulks & & & & & & 3.23 & 3.98 & 3.28 & 3.96 & 0.29 & 0.79 & 79.31 \\
\hline Trial mean & & & & & & 3.79 & 4.31 & 3.33 & 4.31 & 0.30 & 0.64 & 40.41 \\
\hline SE & & & & & & 0.04 & 0.03 & 0.03 & 0.03 & 0.01 & 0.02 & \\
\hline
\end{tabular}

${ }^{1}$ Contains possible intergrades with C. maculata.

${ }^{2}$ Contains probable $C$. henryi.

${ }^{3}$ Means back-transformed from analysed transformed data.

Table 2. - Variance ratios $(\mathrm{F}), \mathrm{Z}$ values, and probability values $(P)$ from mixed model analyses of variance for provenances.

\begin{tabular}{lccccc}
\hline Factor & DBHOB & Height & $\begin{array}{c}\text { Stem } \\
\text { Straightness }\end{array}$ & $\begin{array}{c}\text { Branch } \\
\text { thickness }\end{array}$ & $\begin{array}{c}\text { QSB Damage } \\
\text { (transformed) }\end{array}$ \\
\hline Replicate & $\mathrm{Z}=0.77$ & $\mathrm{Z}=0.90$ & $\mathrm{Z}=0.90$ & $\mathrm{Z}=0.52$ & $\mathrm{Z}=0.89$ \\
& $P=0.219$ & $P=0.183$ & $P=0.185$ & $P=0.301$ & $P=0.187$ \\
Provenance & $\mathrm{F}=2.03$ & $\mathrm{~F}=3.07$ & $\mathrm{~F}=5.06$ & $\mathrm{~F}=5.01$ & $\mathrm{~F}=6.41$ \\
& $P=0.003$ & $P=0.0001$ & $P=0.0001$ & $P=0.0001$ & $P=0.0001$ \\
Family(Prov) & $\mathrm{Z}=1.84$ & $\mathrm{Z}=2.65$ & $\mathrm{Z}=0.28$ & $\mathrm{Z}=0.69$ & $\mathrm{Z}=4.36$ \\
& $P=0.033$ & $P=0.004$ & $P=0.389$ & $P=0.245$ & $P=0.0001$ \\
Rep x Family $=$ & $\mathrm{Z}=1.62$ & $\mathrm{Z}=2.08$ & $\mathrm{Z}=2.58$ & $\mathrm{Z}=2.36$ & $\mathrm{Z}=3.42$ \\
Plot & $P=0.052$ & $P=0.019$ & $P=0.005$ & $P=0.009$ & $P=0.0003$ \\
Residual & 22.80 & 22.87 & 22.73 & 22.73 & 22.87 \\
\hline
\end{tabular}

The poorest provenances for growth included Grange, Marara, Newry, and Washpool, all with mean DBHOB below $3.1 \mathrm{~cm}$ and mean height below $3.7 \mathrm{~m}$ (Table 1). Bagawa, Esk and Girard also ranked very poorly for DBHOB, but not so poorly for height. Most of the NSW provenances in this group were from higher altitudes away from the coast. These provenances contained several families with mean diameters below $3.0 \mathrm{~cm}$ and/or height below $3.5 \mathrm{~m}$. The remaining 15 provenances with relatively good to mediocre mean diameter and height contained among them 20 families with relatively large mean diameter (over $4.3 \mathrm{~cm}$ ) and 14 families with large 
mean height (over $4.8 \mathrm{~m}$ ). The families were mostly superior for both traits. Lowering these mean levels slightly would add considerably more families.

Stem and branch form: Six superior growth provenances - Sugarloaf (putative C. henryi), Brooyar, Home, Wolvi, Wondai and Woondum - were also superior for STR and BRT (i.e. trees with thin branches), and all ranked in the top quarter for both traits (Table 1). The mean of this group was significantly greater than the mean of all other provenances combined for both traits (SAS MIXED Contrasts, $P=0.0001$ ). Chaelundi and Wedding Bells (NSW) also ranked well for mean STR, though they were mediocre for BRT. Esk ranked best for BRT (mean 4.99) but it was relatively poor for STR. No provenances displayed very poor mean STR or BRT, the worst for STR being Mt Belmore, Newry, and Tamban (2.54 to 2.61 points), and the worst for BRT being $\mathrm{Mt}$ Belmore (mean 3.29 points), followed by Gilgurry and Bagawa (3.67-3.70). Home, Wolvi, and Woondum among them contained 14 families with high mean STR $>$ 4.0. Brooyar and Esk contained the greatest proportions of superior BRT families (43 and 33\%). The best family for STR was from Wolvi (mean 4.51) and the best family for BRT was from Esk (mean 6.04). Families with relatively high mean STR and BRT also occurred in small numbers in most of the middle-ranked provenances.

Quambalaria shoot blight: Five of the 31 provenances (excluding Newry, represented by a single family) had mean back-transformed QDI below 18\%; these were Brooyar, Home, Wolvi, Woondum, and Wedding Bells (Table 1). Home, Wolvi, and Woondum had QDI below $6.1 \%$, and also showed superior growth and form. The renowned Woondum provenance had significantly lower QDI than the other combined Queensland provenances and the entire group of 30 other provenances (SAS MIXED Contrasts $P=0.001$ and 0.0001 , respectively).
A second group of five provenances represented by $>1$ family (Chaelundi, Girard, Lower Bucca, Sheas Nob, and Wondai) had mean QDI of about 29 to $32 \%$. The great majority of families within the superior provenances suffered mean damage levels below 25\%; for example, Wedding Bells, Wolvi, Woondum, and Home all had over $80 \%$ of such lightly damaged families. The poorest families in these provenances mostly had relatively light QDI (although one exceptional Woondum family scored $46 \%$ ), and most families scored well below $10 \%$. The single Newry (NSW) family was not infected at all, but it cannot be taken to represent the provenance.

The poorest provenances for QDI were Bagawa, Boonanghi, Gilgurry, Marara, Tamban, and Yessabah, with mean back-transformed damage of over $62 \%$ (Table 1). The most damaged family was from Grange (96\%), but 18 other families in the trial had over $80 \%$ mean damage. The southern-most three provenances, Boonanghi, Tamban and Yessabah had mean back-transformed damage of $67.3 \%$ to $73.5 \%$, and as a group they had a significantly greater mean QDI than the mean of all the other provenances (Contrasts $P=0.0001$ ), and the mean of the other NSW provenances (Contrasts $P=0.0004$ ).

Most of the intermediate-ranked provenances contained families with wide ranges of mean QDI, from about $15-20 \%$ up to $70-80 \%$. There were occasional lightly damaged families and undamaged trees in some of the intermediate and even poorly ranked (i.e. severely damaged) provenances. The Richmond Range provenance, commonly used in NSW plantations, had moderate damage (back-transformed mean of $46.2 \%$ ) and a wide range of family means, with $23 \%$ of families having $<26 \%$ QDI.

The five provenances containing putative $C$. henryi families had moderate to fairly high mean values of QDI, of $30 \%$ to $56 \%$. Individual family mean values var-

Table 3. - Regression coefficients for relationships between back-transformed mean QDI, growth traits, and provenance origins, for 23 well-represented spotted gum provenances and all 194 families.

\begin{tabular}{lcc}
\hline \multicolumn{1}{c}{ Relationship } & $\begin{array}{c}\text { Regression } \\
\text { coefficient } \mathrm{R}^{2}\end{array}$ & $p$ \\
\hline Provenance mean QDI/latitude & 0.51 & 0.0001 \\
Provenance mean QDI/altitude & 0.16 & 0.0554 \\
Provenance mean QDI/annual rainfall & 0.005 & 0.7594 \\
Provenance mean QDI/summer rainfall & 0.002 & 0.8319 \\
Provenance mean DBHOB/QDI & 0.49 & 0.0002 \\
Provenance mean HT/QDI & 0.58 & 0.0001 \\
Family mean DBH/QDI & 0.20 & 0.0001 \\
Family mean HT/QDI & 0.29 & 0.0001 \\
\hline
\end{tabular}


ied widely, from $0.2 \%$ to $80.5 \%$. Three families (from Lockyer and Sugarloaf) had $<20 \%$ mean CDI.

Fork and ramicorn counts: Mean values for provenances are shown in Table 1. Mean ramicorn counts were considerably greater than fork counts in most provenances. Several provenances with a low mean fork number $(<0.25)$ also had a low mean ramicorn count $(<0.45)$, including Brooyar, Home, Lockyer, Wolvi, Wondai, Woondum, and Mt Pikapene (single family). Extra provenances considered superior included
Chaelundi, Gilgurry, and Sheas Nob (for fork count), and Ingalba, Newry (single family), and Sugarloaf (for ramicorn count). There were only two notably "forky" provenances, with mean $>0.6$ (Boonanghi and Mount Belmore). In contrast there were seven provenances with a mean ramicorn count of 1.0 or higher, viz. Bagawa, Gilgurry, Grange, Kangaroo River, Mt Belmore, Tamban, and Yessabah.

Superior or poor provenances for fork or ramicorn count tended to contain high proportions of respectively

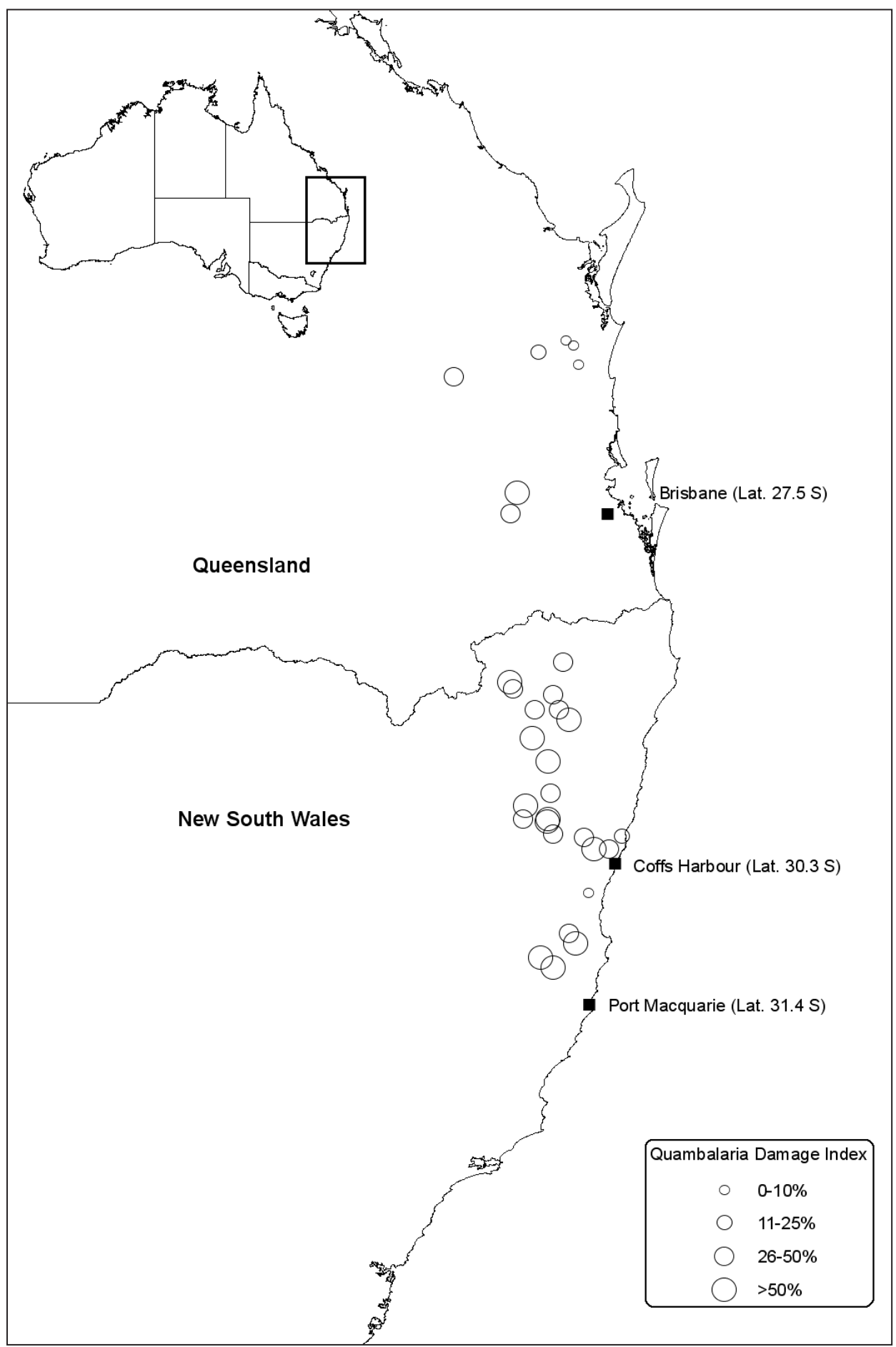

Figure 1. - Map of northeast NSW and southeast Queensland showing origins of families assessed in trial, with graduated circles depicting Quambalaria Damage Index for provenances. 


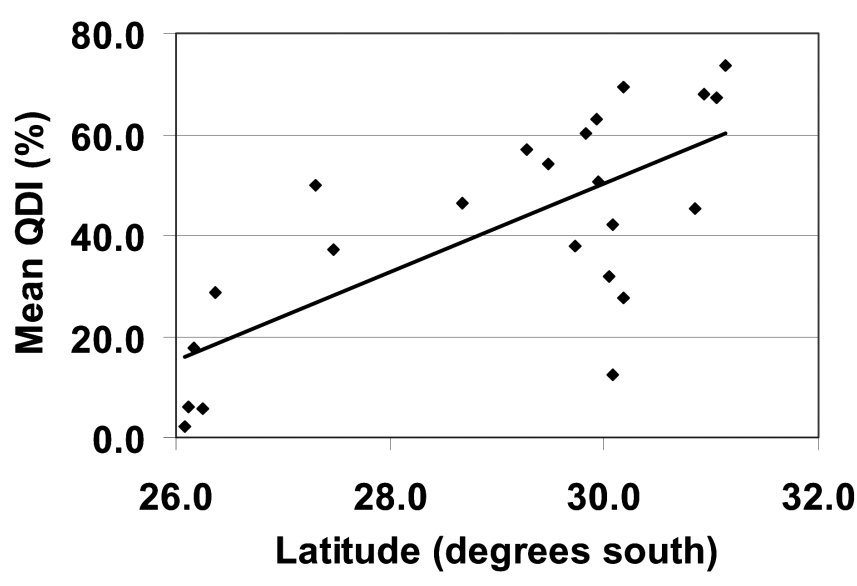

Figure 2. - Regression of back-transformed mean QDI on latitude of origin, for 23 well-represented spotted gum provenances.

$\mathrm{R}^{2}=0.51$. Mean QDI $=-213.23+8.78 *$ latitude $P=0.0001$.

superior or poor families. This was most pronounced in poor provenances for ramicorn count with 4-plus families, such as Bagawa, Grange, Kangaroo River, Tamban, and Yessabah, in which 75 to $100 \%$ of families were poor.

\section{Relationships between Quambalaria shoot blight and genotype origins}

There was significant (though not strong) linear regression of back-transformed mean QDI for 23 wellrepresented provenances (those having 4 or more families) on latitude $\left(\mathrm{R}^{2}=0.51, P=0.0001\right)$, but not on altitude $\left(\mathrm{R}^{2}=0.16, P=0.055\right)$, of provenance origin (Table 3 ). QDI increased as latitude increased (i.e. more southerly) (Figures 1 and 2). The moderately high $\mathrm{R}^{2}$ for latitude no doubt resulted from a cluster of four Queensland provenances from about latitude $26^{\circ} \mathrm{S}$, with very low mean damage, and another small cluster of NSW provenances originating at about latitude $31^{\circ} \mathrm{S}$, with high mean damage. QDI values for the majority of the provenances, originating from about $29-30^{\circ} \mathrm{S}$, varied widely (Fig. 2 and Tables 1 and 3). There was a paucity of

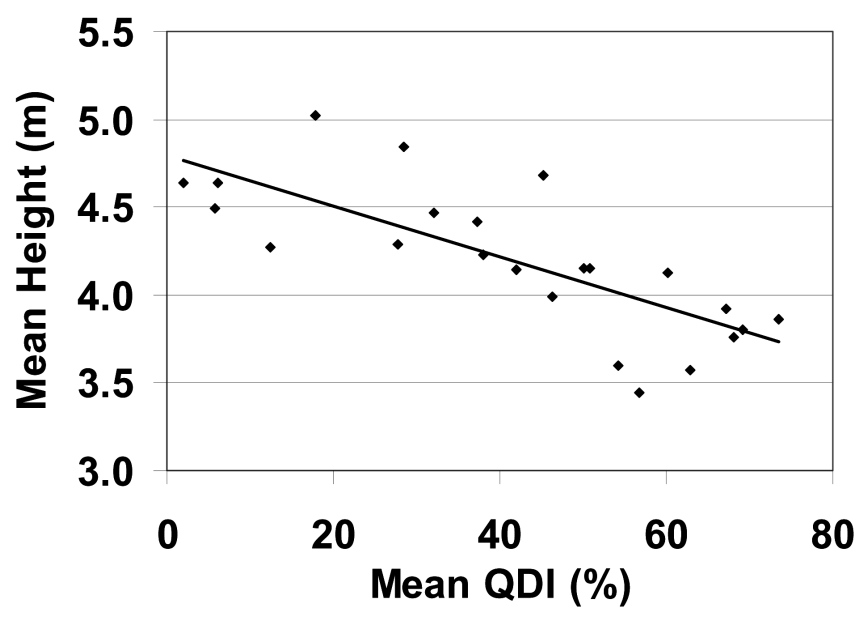

Figure 3. - Regression of mean height on back-transformed mean QDI, for 23 well-represented spotted gum provenances. $\mathrm{R}^{2}=0.58 ;$ Height $=-0.0191 *$ mean QDI $+4.9889 ; P<0.0001$.
Table 4. - Components of variance for random effects: familiesin-provenances $\left(\sigma_{\mathrm{f}}^{2}\right)$, replicate $\mathrm{x}$ family interaction (or plot) $\left(\sigma_{\mathrm{fr}}^{2}\right)$, and residual $\left(\sigma_{\mathrm{e}}^{2}\right)$, from analyses of 178 families from well represented provenances. Used to estimate heritability.

\begin{tabular}{lccc}
\hline \multicolumn{1}{c}{ Trait } & $\sigma_{\mathrm{f}}^{2}$ & $\sigma_{\mathrm{fr}}^{2}$ & $\sigma_{\mathrm{e}}^{2}$ \\
\hline DBHOB & 0.0893 & 0.1589 & 2.2718 \\
Height & 0.0819 & 0.0976 & 1.2796 \\
Straightness & 0.0 & 0.08978 & 0.8313 \\
Branch thickness & 0.0156 & 0.0805 & 0.8887 \\
& & & \\
Arcsin sqrt QDI & 109.380 & 99.805 & 679.95
\end{tabular}

points in the $27^{\circ}$ to $29^{\circ}$ range. Wedding Bells was a clear outlier, originating near $30^{\circ} \mathrm{S}$ but with a much lower mean QDI (12.5\%) than other provenances from near this latitude. Regressions of provenance QDI on annual and summer rainfall at provenance origin were effectively nil, for all provenances and for the 23 wellrepresented provenances $\left(\mathrm{R}^{2}=0.002\right.$ to $0.009 ; P=0.61$ to 0.83 ).

\section{Relationships between Quambalaria shoot blight and growth}

Regressions of mean growth on back-transformed mean QDI were highly significant $(P<0.0002)$ for both DBHOB and HT, for all families and for the 23 well-represented provenances. Mean growth decreased with increasing mean QDI. Values of $\mathrm{R}^{2}$ were higher for provenances $(0.49$ and 0.58$)$ than for families $(0.20$ and 0.29 ), and greatest for height on QDI in both cases (Table 3). The regression of mean height on back-transformed mean QDI for provenances is shown in Figure 3.

For all individual trees assessed, and within provenances represented by several families, there was a tendency for height and diameter to fall as QDI increased (data not presented). The regressions in the case of all trees combined were very weak, though statistically significant $\left(R^{2}=0.132\right.$ for height, and 0.079 for diameter; $P=0.0001$ ). Regression of height on QDI was also very weak within all individual provenances $\left(R^{2}=0.0\right.$ to $0.43)$, although these regressions were significant for 22 of 30 provenances. Regression of $\mathrm{DBH}$ on QDI was weaker than for height, and significant for only 13 provenances.

\section{Genetic and phenotypic parameters}

Variance components derived from the 178-family data set to estimate heritability are shown in Table 4 . The individual heritability estimates for growth and form traits ranged from zero (STR) to low (0.09 and 0.14 ) for $\mathrm{DBHOB}$ and $\mathrm{HT}$, respectively, and with relatively large standard errors at least $50 \%$ to $80 \%$ of the estimates. The estimate for transformed QDI was 
Table 5. - Heritability estimates and additive genetic and phenotypic correlation estimates for spotted gum family seedlots. Genetic correlations (with standard errors) above diagonal, phenotypic correlations (with SE) below diagonal; heritability estimates with SE on diagonal (individual estimate above, family estimate below).

\begin{tabular}{ccccccc}
\hline Trait & DBHOB & Height & $\begin{array}{c}\text { Stem } \\
\text { Straightnes } \\
\text { S }\end{array}$ & $\begin{array}{c}\text { Branch } \\
\text { Thickness }\end{array}$ & QDI $^{1}$ & No. Forks \\
\hline DBHOB & $\mathbf{0 . 0 9 ( 0 . 0 7 )}$ & & & & $-0.88(0.34)$ & \\
Height & $\mathbf{0 . 2 3 ( 0 . 0 5 )}$ & & & & \\
& 0.91 & $\mathbf{0 . 1 4}(\mathbf{0 . 0 8})$ & & & & \\
Stem Straightness & $0.004)$ & $\mathbf{0 . 3 2}(\mathbf{0 . 0 5})$ & & & & \\
& 0.37 & 0.48 & $\mathbf{0 . 0 0}$ & & & \\
Branch Thickness & $(0.022)$ & $(0.019)$ & $\mathbf{0 . 0 0}$ & & & \\
& -0.17 & 0.02 & 0.26 & $\mathbf{0 . 0 4}(\mathbf{0 . 0 6})$ & & \\
QDI & $(0.025)$ & $(0.025)$ & $(0.023)$ & $\mathbf{0 . 1 2}(\mathbf{0 . 0 4})$ & & \\
& -0.30 & -0.38 & -0.44 & -0.27 & $\mathbf{0 . 3 1}(\mathbf{0 . 0 9})$ & \\
No. Forks & $(0.024)$ & $(0.022)$ & $(0.021)$ & $(0.024)$ & $\mathbf{0 . 5 0}(\mathbf{0 . 0 7})$ & \\
& -0.03 & -0.11 & -0.39 & -0.11 & 0.14 & \\
No. Ramicorns & $(0.026)$ & $(0.025)$ & $(0.022)$ & $(0.025)$ & $(0.025)$ & \\
& -0.22 & -0.35 & -0.48 & -0.21 & 0.38 & 0.12 \\
& $(0.025)$ & $(0.023)$ & $(0.020)$ & $(0.025)$ & $(0.021)$ & $(0.025)$ \\
\hline
\end{tabular}

${ }^{1}$ Transformed data used for this trait.

$0.31 \pm 0.09$, a moderate value. Family mean heritability (other than for STR) was low to moderate (0.12 for BRT to 0.50 for QDI), with low standard errors (Table 5).

Genetic correlations were only estimated for transformed QDI and the growth traits, as individual heritability estimates for the three form traits were very low or zero. Correlations for transformed QDI with each of DBHOB and HT were strong and negative $(-0.88$ and -0.77 ), with low to moderate standard errors $38 \%$ and $27 \%$ of the estimates (Table 5).

All phenotypic correlations from the 178-family data set were statistically significant $(P<0.002)$ apart from those for height/branch thickness and DBHOB/number of forks, and standard errors were mostly very low (Table 5). This was mainly due to the large number of individual trees in the data set. Only the correlation between DBHOB and HT was high $(r=0.91)$. The correlations between growth and STR were weak and positive ( $r=0.37$ and 0.48$)$, and BRT was weakly positively correlated with straightness (0.26). Transformed QDI was weakly, negatively correlated with DBHOB and HT (-0.30 and -0.38$)$, and also with STR and BRT $(-0.44$ and -0.27$)$. Fork and ramicorn counts were positively but weakly correlated with QDI, the latter more strongly $(\mathrm{r}=0.38)($ Table 5).

\section{Discussion}

In this trial, we identified provenances and families of C. citriodora subsp. variegata that were superior for growth, form and Quambalaria shoot blight tolerance. Notably superior provenances, each represented by several families, were Home, Wolvi, and Woondum (southeast Queensland). Dickinson et al. (2004) also found Woondum provenance to be lightly damaged by Quambalaria shoot blight in taxon x site trials in Queensland. It was superior to all (between one and three) other provenances of $C$. citriodora subsp. variegata in 14 out of 19 trials, and also had the best height growth on nine sites. In contrast, Woondum was not outstanding in tolerance in an inoculation study in Queensland (SELF et al., 2002), having a percentage of infected foliage greater than Richmond Range, but not significantly so $(21.1 \%$ vs $13.8 \%)$. This result was contrary to those in the present study. However, the inoculation trial only included five C. citriodora subsp. variegata provenances, and the number of families contributing to the single Woondum seedlot is not known. There was only a limited number of seedlings assessed per provenance (25).

At the single site where it was planted in the Queensland taxon trials, Wolvi provenance was moderately to severely infected, and had relatively poor early height growth. However, the provenance seedlot used was collected from only four trees (Dickinson et al., 2004). In the present trial, Wolvi provenance was superior in growth and tolerance (with 6.0\% mean damage) and better represented, by 13 families, but these did include four families with moderate mean QDI of 21-38\% (though not necessarily the same families as in the Queensland trial).

Of the 79 families in the present trial with mean Quambalaria shoot blight under 25\%, 52 were from the south-east Queensland provenances of Brooyar, Home, Wolvi, Wondai, and Woondum, making them obvious sources of tolerant genotypes. Mean DBHOB and HT growth of many of the tolerant families was also superior. Wedding Bells (coastal NSW) was also outstanding for Quambalaria shoot blight tolerance, but with only one high-growth family. The superior tolerance of Wedding Bells was possibly related to its coastal location (the coastal provenance Newry also had very low infection, but was represented by only one family). However, there were too few NSW coastal provenances to suggest a consistent trend. Families combining superior DBHOB 
( $>4 \mathrm{~cm}$ ) and superior mean tolerance $(<30 \%$ damage) occurred in a few other provenances ranked lower for Quambalaria shoot blight tolerance, but they were uncommon (10 families).

SELF et al. (2002) considered that the significant variation in Quambalaria shoot blight tolerance existing within provenances could be utilised in tree improvement by selecting some outstanding families or individuals from unexceptional provenances. Such a strategy would be desirable for selecting genotypes for breeding from the present trial, to broaden the genetic base beyond families from a few superior Queensland and NSW provenances. Ten families from mediocre $C$. citriodora subsp. variegata provenances that combined superior mean growth and low mean QDI (mentioned above), came from seven provenances including Boonanghi, Dalmorton, Ewingar, Ingalba, Kangaroo River, Ramornie, and Richmond Range. Individual trees with height over $6 \mathrm{~m}$ and QDI below 5\% existed in several provenances that showed moderate to high mean damage and mediocre mean growth (e.g. Kangaroo River, Richmond Range, and Dalmorton). Such trees could be useful for broadening a breeding population.

Families from the southern provenances (Boonanghi, Ingalba, Tamban, and Yessabah), which probably contained $C$. maculata or intergrades of $C$. citriodora subsp. variegata with that species, were mostly highly damaged by Quambalaria shoot blight. A few of the southern families displayed fairly high mean diameter growth, although this was mostly accompanied by high QDI. This is consistent with the significant correlation between QDI and provenance latitude $\left(\mathrm{R}^{2}=0.51\right)$.

There is a paucity of information on the relative susceptibilities of $C$. maculata and $C$. citriodora subsp. variegata. CARNEGIE (2007b) reported lower disease levels in plantations of $C$. citriodora subsp. variegata in NSW (established from 2000 onwards) compared to earlier plantings of C. maculata (established 1995-1999) during surveys over a 10-year period, although he could not rule out climate differences between these periods as a factor. Conversely, in a "crop loss" study on two sites in northern NSW, C. citriodora subsp. variegata from Warwick (sub-inland Queensland) and Moleton (north-west of Coffs Harbour, NSW) were both more damaged by a combined range of fungi (including $Q$. pitereka) than was $C$. maculata from the NSW South Coast (SIMPSON et $a l ., 1997)$. The inland Warwick provenance was the most damaged of the three, and also had the poorest mean height growth. In a 6-year-old species trial on the central coast of NSW, a low-rainfall provenance of C. maculata (Curryall, NSW) had significantly lower means for $\mathrm{DBH}$ and height $(4.5 \mathrm{~cm}$ and $4.5 \mathrm{~m})$, and higher QDI (35\%), than the combined means of three provenances of C. citriodora subsp. variegata (DBH $14.0 \mathrm{~cm}$, height 13.0 m, QDI 2.5\%) (A. Carnegie, unpubl. data). However, the C. maculata tested was not representative of "core" areas of the species' range on the NSW central and south coasts.

There was effectively no correlation between mean provenance Quambalaria shoot blight and rainfall at the seedlot origins in our trial. In contrast, Dickinson et al.
(2004) reported that mean annual rainfall at provenance origin was a good indicator of potential Quambalaria shoot blight tolerance in spotted gums: provenances in Queensland trials originating from higher rainfall, coastal areas (e.g. Woondum) were more tolerant of Quambalaria shoot blight than those from drier inland areas (e.g. Carnarvon, Queensland). Similar observations have been made for other diseases, such as Mycosphaerella leaf disease (CARNEGIE et al., 1994; 2004) and target spot caused by Aulographina eucalypti (CARNEGIE and KEANE, 2003) on a range of species of Eucalyptus. It was postulated that provenances from warmer, wetter areas would have co-evolved with the pathogen(s), and therefore built up some tolerance (CARNEGIE et al., 1994, 2004). C. citriodora subsp. variegata provenances of low annual rainfall $(630-750 \mathrm{~mm})$ were present in the Queensland trials (DICKINSON et al., 2004), but there were no provenances with rainfall this low in the present trial. Relatively low rainfall provenances such as Esk, Lockyer and Wondai $(\mathrm{MAR}=800-850 \mathrm{~mm}$ ) had moderate mean QDI (29 to $50 \%$ ). The lack of contrast in provenance rainfalls may have lowered the power of this correlation.

Four of the ten putative $C$. henryi families in the trial had relatively low back-transformed QDI means $(0.2 \%$ to $29 \%$ ), and the mean overall for the species was moderate (and very close to the trial mean), at $39.5 \%$. Overall means for DBHOB and height were slightly above the trial means, although four of the families had both DBHOB and height well above trial means. These results suggest about average Quambalaria shoot blight tolerance and slightly above average growth for $C$. henryi on this site, but firm conclusions cannot be made since the $C$. henryi complement of the trial was not firmly identified. On moister site $\mathrm{x}$ taxon trial sites in Queensland (>800 $\mathrm{mm}$ rainfall), provenances of this species were moderately to severely damaged by Quambalaria shoot blight, much more so than Woondum, but similarly to some inland $C$. citriodora subsp. variegata provenances. It had lower height growth than most C. citriodora subsp. variegata provenances on the wetter sites, but on drier sites the two species tended to be similar for both damage and height (DICKINSON et al., 2004). Five NSW provenances of $C$. henryi showed good growth (mean 6.1 to $7.0 \mathrm{~m}$ ) at 54 months on one moist, fertile Queensland site, but no other taxa were tested with them (DiCKINSON et al., 2004). In most of these Queensland trials, there were only between one and three provenances of each species compared. In a nursery trial, SELF et al. (2002) found a single provenance seedlot of $C$. henryi (Myrtle Creek, NSW) to have a similar, fairly low, percent of foliage infected to Woondum provenance $C$. citriodora subsp. variegata: $19.8 \%$ vs. $21.1 \%$. However, LEE (2007) stated that no Quambalaria shoot blight-tolerant provenance of $C$. henryi had been found from tree improvement work in Queensland.

Individual heritability estimates for growth traits in the current trial were low (c. 0.1), which is generally consistent with most estimates of these traits in wild progenies of other eucalypt species, e.g. 0.14-0.16 for DBHOB and 0.19-0.22 for height in 3-year-old $E$. dunnii (JOHNSON and ARNOLD, 2000); 0.14 for volume of young 
E. pilularis (CARNEGIE et al., 2004). However, estimates for 3.5-year-old E. cladocalyx in Western Australia (WA) were moderate (0.40-0.44 (CALLISTER et al., 2008). The zero heritability for STR in the present trial was probably due to the mostly small tree size. In other species at young ages, low to moderate estimates have been recorded for this trait - e.g. E. dunnii 0.11 (JOHNSON and ARNOLD, 2000); young E. cladocalyx 0.16 to 0.50 in WA (CALlister et al., 2008); 0.15 for 60-month old E. camaldulensis in Pakistan (MAHMOUD et al., 2003). The very low estimate for BRT (0.04) in this trial may be caused by the narrow crown shape in young spotted gums, which makes the differentiation of relative branch thickness difficult. Low heritability values $(0.03$ to 0.17$)$ for branch score in young $E$. cladocalyx in WA (based on a similar method to the current trial) were recorded in WA (CALlister et al., 2008). The individual heritability estimate for QDI (0.31) in the present trial was generally similar to those for other disease traits of eucalypts, e.g Mycosphaerella leaf disease of E. globulus (0.35, Dungey et al., 1997, CARNEGIE and ADES, 2005) and E. pilularis (0.38, CARNEGIE et al., 2004).

The quite strongly negative genetic correlations between transformed QDI and the growth traits $(-0.88$ for DBHOB) suggest that faster-growing families would also have lower Quambalaria shoot blight susceptibility. The significant regressions of height and diameter on Quambalaria shoot blight, for all individual trees, families, and provenances with four or more families indicated that the damage was negatively affecting growth. Only $25 \%$ of severely damaged trees (QDI $>60 \%$ ) were above average in DBHOB, compared with $50 \%$ of lightly damaged trees (QDI <25\%). However, the regressions for all trees combined in our trial were weak and not useful for predicting the effects of different levels of Quambalaria shoot blight damage on growth rate. The measured effect of QDI on tree growth may have been diminished by the practice of assessing the immature foliage only (not the whole crown). Trees with high QDI but a low percentage of immature leaves could be less impacted than trees with low-medium QDI levels and a greater percentage of immature leaves, as overall there is less leaf area damaged. An assessment method that more accurately quantifies the damage and impact of QSB has recently been developed (PEGG and CARNEGIE, 2008, unpubl.).

Overall, our results indicate that Quambalaria shoot blight had a detrimental effect on growth of young spotted gum. Several authors have reported that $Q$. pitereka causes growth loss of spotted gums, but mainly from field observations (e.g. SIMPSON, 2000; CARNEGIE, 2007b; PEGG et al., 2008, 2009). Dickinson et al. (2004) noted, from a provenance study over 22 sites in Queensland, that variation among spotted gum provenances in early height growth appeared to be closely associated with severity of Quambalaria shoot blight, especially on higher rainfall sites (although no regression results were given). Growth reduction is not surprising, considering that $Q$. pitereka infects the growing shoots, causing death of these in most cases, leaving the top third or so of severely infected trees dead. Severe and repeated Quambalaria shoot blight also results in poor stem form
(SIMPSON et al., 1997; Simpson, 2000; CARNEGIE, 2007b; PEGG et al., 2008), potentially reducing the value of sawlogs. Families and provenances in this trial with high mean QDI tended to have poor mean straightness scores and above average numbers of forks and ramicorns, although the phenotypic correlations were weak. Studies are currently underway to quantify the longterm impact of Quambalaria shoot blight on spotted gums, including the impact on merchantable volume of trees.

Our results indicate that there is ample scope for selection within the range of provenances and families in current breeding stock to improve Quambalaria shoot blight tolerance, growth and form of spotted gum, and to reduce the future impact of the disease in commercial plantations in sub-tropical Australia. Applying theoretical culling levels of $4.0 \mathrm{~cm}$ for DBHOB and $30 \%$ for Quambalaria shoot blight damage, in the present trial, gave $49.4 \%$ of "acceptable" trees overall in the three best provenances based on mean QDI (Home, Wolvi, and Woondum). In practice, phenotypic thinning to waste at about three years (as done in Queensland) in stands of equivalent quality might be able to retain at least half of the trees as acceptable. It is encouraging that even on such a relatively poor site as this trial, the use of select provenances may give worthwhile gains in growth and Quambalaria shoot blight tolerance. Seed orchards are being developed, utilising the resource of superior families and individual trees in the trial that combine superior growth and Quambalaria shoot blight tolerance, to achieve more substantial gains in these traits.

\section{Acknowledgements}

Seed of Queensland families was provided by the then Queensland Forest Research Institute, under a cooperative agreement between the two State agencies. We thank DARREL JOHNSTONE and JIM O'HARA of Forests NSW, who diligently supervised trial establishment and carried out growth and form assessments of the trial. Assistance from field staff of Forests NSW in preparing and maintaining the site is much appreciated. MiLosH IvKovich and CoLIN MATHESON kindly assisted with data analysis.

\section{References}

Bertus, A. L. and J. WALKer (1974): Ramularia on Eucalyptus and Angophora. Australasian Plant Pathology Society Newsletter 3: 3 .

Boland, D. J., M. I. H. Brooker, G. M. Chippendale, N. Hall, B. P. M. Hyland, R. D. Johnston, D. A. Kleinig and J. D. TURNER (1984): Forest Trees of Australia. Nelson/CSIRO. 687 pp.

Bootle, K. R. (1983): Wood in Australia - Types, properties and uses. McGraw-Hill Book Company, Sydney.

Callister, A., D. Bush, S. Collins and W. Davis (2008): Prospects for genetic improvement of Eucalyptus cladocalyx in Western Australia. New Zealand Journal of Forestry Science 38(1): 211-226.

CARNEGIE, A. J. (2007a): Forest health condition in New South Wales, Australia, 1996-2005. I. Fungi recorded in eucalypt plantations during forest health surveys. Australasian Plant Pathology 36, 213-224. 
CARNEGIE, A. J. (2007b): Forest health condition in New South Wales, Australia, 1996-2005. II. Fungal damage recorded in eucalypt plantations during forest health surveys and their management. Australasian Plant Pathology 36, 225-239.

Carnegie, A. J., P. J. Keane, P. K. Ades and I. W. Smith (1994): Variation in susceptibility of Eucalyptus globulus provenances to Mycosphaerella leaf disease. Canadian Journal of Forest Research 24: 1751-1757.

Carnegie, A. J. and P. K. Keane (2003): Variation in severity of target spot, caused by Aulographina eucalyp$t i$, in a eucalypt species and provenance trial in Victoria. Australasian Plant Pathology 32: 393-402.

Carnegie, A. J., I. G. Johnson and M. Henson (2004): Variation among families and provenances of blackbutt (Eucalyptus pilularis) in early growth and susceptibility to damage from leaf spot fungi. Canadian Journal of Forest Research 34, 2313-2326.

Carnegie, A. J. and P. K. Ades (2005): Variation in Eucalyptus globulus in susceptibility of adult foliage to leaf diseases caused by species of Mycosphaerella. Silvae Genetica 54, 174-184.

Dickinson, G. R., D. J. LeE and J. R. Huth (2004):. Early plantation growth and tolerance to Quambalaria Shoot Blight of provenances of three spotted gum taxa on a range of sites in Queensland. Australian Forestry 67(2): $122-130$

Dungey, H. S., B. M. Potts, A. J. CARnegie and P. K. Ades (1997): Mycosphaerella leaf diseases: Genetic variation in damage to Eucalyptus nitens, E. globulus and their $\mathrm{F}_{1}$ hybrid. Canadian Journal of Forest Research 27: 750-759.

ELDRIDGE, K. G. (1973): Minimum standards for evaluating progeny trials of Pinus radiata. Proc IUFRO Meeting on Tropical Provenance and Progeny Research and International Cooperation, Nairobi, Kenya, pp 477-480.

EldRIDGe, K., J. Davidson, C. Harwood and G. VAN WyK (1994): Eucalypt Domestication and Breeding. Oxford Scientific Publications. 288 pp.

GaVran, M. and M. PARsons (2008): National Plantation Inventory 2008 Update. National Forest Inventory, Bureau of Rural Sciences, Canberra.

Gilmour, A. R., B. J. Gogel, B. R. Cullis, S. J. Welham and R. Thompson (2002): ASReml User Guide Release 1.0. VSN International Ltd, Hemel Hempstead, HP1 $1 \mathrm{ES}, \mathrm{UK}$.

HAMmer, Ø., D. A. T. HARPER and P. D. RYAN (2001): PAST: Paleontological statistics software package for education and data analysis. Palaeontologia Electronica 4(1). $9 \mathrm{pp}$.

HiLL, K. D. and L. A. S. Johnson (1995): Systematic studies in the eucalypts. 7. A revision of the bloodwoods, genus Corymbia (Myrtaceae). Telopea 6: 185-504.

Houlder, D., M. Hutchinson, H. Nix and J. McMahon (2001): ANUCLIM Version 5.1 Users Guide.

Johnson, I. G. and R. J. ARNOLD (2000): Eucalyptus dunnii provenance-family trials in Northern New South Wales - age three-year assessment. State Forests of NSW Research Paper No. 37.

LEE, D. (2007): Achievements in forest tree genetic improvement in Australia and New Zealand 2: Development of Corymbia species and hybrids for plantations in eastern Australia. Australian Forestry 70, 11-16.

Mahmood, K., N. E. Marcar, M. H. Naqvi, R. J. Arnold, D. F. CRAwFord, S. IQBAL and K. M. AKEN (2003): Genetic variation in Eucalyptus camaldulensis Denh. for growth and stem straightness in a provenance-family trial on saltland in Pakistan. Forest Ecology and Management 176, 405-416.

MCDonald, M.W. and A. R. BeAn (2000): Note: A new classification in Corymbia 'section Politaria': C. citriodora subsp. variegata (Myrtaceae). Austrobaileya 5(4): 735-736.

Nichols, J. D., G. R. B. Smith, K. Glencross and J. GRANT (2008): Subtropical Eucalypt Plantations in Australia: a new opportunity and challenge. pp 96-101 in Proceedings. Presented at Australian Forest Growers Conference, Albury, NSW, Australia, 20-22 October 2008.

Nikles, D. G., D. J. Lee, K. J. Robson, P. C. Pomroy and S. W. WALKER (2000): Progress on species selection trials and genetic improvement for hardwoods for commercial plantings in Queensland. In: SNELL, A. and VISE S. (Eds) Opportunities for the New Millennium. Proc. Australian Forest Growers Conference, Cairns, Aust., Sept 2000, pp. 23-31.

OLD, K. M., (1990): Diseases caused by fungi. In: Cremer, K. W., ed. Trees for Rural Australia. Inkata Press, Melbourne.

PegG, G. S., C. O’Dwyer, A. J. Carnegie, T. I. Burgess, M. J. WingField and A. DRenth (2008): Quambalaria species associated with plantation and native eucalypts in Australia. Plant Pathology 57: 702-714.

PEGG, G. S., A. J. CARnEGIE, M. J. Wingfield and A. DRENTH (2009): Quambalaria spp.: increasing threats to eucalypt plantations in Australia. Southern Forests 71 (2): 111-114.

Pryor, L. D. and L. A. S. Johnson (1971): A classification of the eucalypts. Australian National University Press: Canberra.

SAS INSTITUTE INC. (1990): SAS ${ }^{\circledR}$ Procedures Guide, Version 6, Third Edition, Cary, NC: SAS Institute Inc. $705 \mathrm{pp}$.

SAS INSTITUTE INC. (1996): SAS/STAT ${ }^{\circledR}$ Software: Changes and Enhancements through Release 6.11, Cary, NC. 1104 pp.

Self, N. M., E. A. B. Aitken and M. D. Dale (2002): Susceptibility of provenances of spotted gums to Ramularia shoot blight. New Zealand Plant Protection 55: 68-72.

Simpson, J. A. (2000): Quambalaria, a new genus of eucalypt pathogens. Australasian Mycologist 19, 57-62.

Simpson, J. A., C. Stone and R. EldRIDGe (1997): Eucalypt plantation pests and diseases - crop loss study. Forest Research and Development Div., State Forests of NSW Research Paper No. 35. 33 pp plus appendices.

Stone, C., J. A. Simpson and R. GitTens (1998): Differential impact of insect herbivores and their fungal pathogens on the Eucalyptus Subgenera Symphyomyrtus and Monocalyptus and the Genus Corymbia. Australian Journal of Botany 46, 723-734.

Stone, C., M. Matsuki and A. J. Carnegie (2003): Pest and disease assessment in young eucalypt plantations: field manual for using the Crown Damage Index, ed. Parsons, M. National Forest Inventory, Bureau of Rural Sciences, Canberra.

WALKeR, J. and A. L. BeRTUs (1971): Shoot blight of Eucalyptus spp. caused by an undescribed species of Quambalaria. Proceedings of the Linnean Society of NSW 96, 2108-2117.

Williams, E. R. and A. C. Matheson (1994): Experimental Design and Analysis for Use in Tree Improvement. CSIRO Publishing. 